\title{
Vibration exposure of workers: considerations on some technical and interpretative aspects of the EC standards recently issued
}

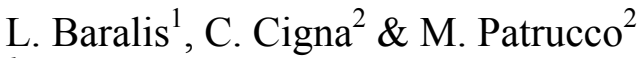 \\ ${ }^{1}$ ARES S.r.l., Torino (TO), Italy \\ ${ }^{2}$ DITAG, Politecnico di Torino, Torino (TO), Italy
}

\begin{abstract}
The 2002/44/CE directive on occupational vibrations exposure, following the trend introduced with the recent review of the related ISO standards (ISO 2631 and ISO 5349), rises to great evidence the problem of an effective evaluation and management of the vibration related risk; but, since the aforesaid directive is not yet enforced in Italy, the new approach suggests a pause of reflection. This directive, with the necessary differences, adopts evaluation and protection criteria substantially common to those used for a number of physical risks, in particular for noise exposure assessment. However it introduces important modifications, in particular for whole-body exposure, previously commonly considered as an ergonomic problem, and now positively included in the list of occupational factors which can cause health impairment. In any case the introduction of assessment criteria adopted at European level will stimulate further investigations on this risk factor, still poorly known. It still remains in fact to fully understand the intrinsic relation between exposure parameters, related pathologies and the possibility to correlate and to quantify the interference between vibration exposure and other noxious agents (e.g. microclimatic conditions or problems related to cumulative trauma or efforts). The hope is that the compulsory respect of exposure limits now clearly defined, together with the growing conscience of the importance - even in terms of workers health protection - of the former directive 89/392/EEC will lead to a great impulse for the introduction of equipment specially engineered to reduce the vibrations emission at the source, for a revision of work organization and procedures, and for the improvement of the currently available individual protection devices. The paper discusses the results of some measurement campaigns of worker exposure recently carried out, and investigates the available updated control measures, according to the target levels provided by the new European standards; some comments are also summarized about the national situation.
\end{abstract}

Keywords: vibration exposure, occupational safety and health, machinery, EC standards, risk management. 


\section{Introduction}

The European directive 2002/44/CE concerning occupational exposure to mechanical vibrations, closes a long administrative procedure and fills an important gap in the European normative scenario; following the recent review of ISO standards on this matter (ISO 2631 and ISO 5349), points out some problems about a correct and effective approach and risks management for workers health related to vibrations exposure.

However, though the subject is taking ever-increasing weight, there are still some problems to solve. First of all, also if vibration-related risks have been well known since a long time, control methodologies cannot yet be considered well consolidated and the approach to vibration related risk analysis and management is not yet completely shared by the whole international technical and medical community.

\subsection{Relationship with other EC directives}

Evaluation and protection criteria proposed by the EC directive "44" (vibrations) are substantially comparable to those defined for the assessment and control of a large number of physical risks, particularly for the noise risk assessment. This is of course not surprising, as all those documents come from the same 89/391/CEE parent directive.

In a previous draft version of the directive on physical risk assessment (draft directive 93/C77/02 CEE, that never became an official EC directive), there was the very interesting concept of "attention" threshold level (at exposure values lower than recognized action levels) to be used as a guideline and a target level in the risk management and control phase, this "attention level" could have taken great advantages in order to protect workers health, due to the statistical and epidemiological meaning of any threshold limit; unfortunately the draft directive 93/C77/02 CEE was given up and there are no signs of any attention level in final "noise" and "vibration" directives.

Anyway, according to a well established methodology, both the noise and the vibration directives adopt an evaluation approach based on the preventive estimate of the effective workers' exposure, supported by a specific measurement campaigns and a comparison with a quantitative criterion.

In comparison with the EC directive 2003/10/EC (noise), we can recognize in the vibration related document a more pronounced trend leading from an objective exposure "assessment", based on the measurement of suitable parameters, towards the "evaluation" approach, if possible supported by measurements. Such trend, moreover, is already supported by reference, guidelines documents and published data banks of sound pressure levels [1] and values of vibration acceleration data [2], [3] [4] from official national and international sources.

The authors are in any case deeply convinced that an exposure estimate based only on data drawn from data bases can't totally fulfill basic requirements of 89/391 European directive, where a particular situation designed risk analysis is required. 
Further evaluation criteria may relate to data supplied from the machinery manufacturer in order to comply with the related European directives and national laws. From these manufacturer machinery data it should be possible to have info about typical exposure level at work place both for ordinary conditions and for different kinds of operations or machinery tools and equipment. In addition, a series of factors influencing real vibration exposure levels depend on the machinery user: these factors can be quite simple and recognizable ones, as misuse of control measures, or they can involve complex aspects, as maintenance policies (e.g. if periodic maintenance policy is considered, real exposure levels can be significantly far from the ideal estimates for most of the time).

In fact it is a well known fact that the vibratory solicitation generally cannot be defined as a particular feature arising from a specific machinery, but it is produced by the interaction of the same machinery and its working environment (roads and tracks, worked materials, accessories, etc.) and by, when pertinent, the operator actions. All these factors significantly differ from reference test condition stated for any machinery type for certification purpose. Therefore, if data supplied from the manufacturer, can avoid, in some situations, to perform expensive measurement campaigns, on the other side they introduces a wide range of uncertainty.

The following data table shows some outstanding disagree between measured and declared data, met in measurement campaigns carried out by the authors in their respective professional activities. Reference to customer, manufacturer and model of machinery are voluntarily omitted.

Table 1: Comparison between measured values following ISO 5349 standard in real working conditions and values declared by the manufacturer (*) Following national laws, "Not Declared" should be considered as "less than $2,5 \mathrm{~m} / \mathrm{s}^{2}$ ".

\begin{tabular}{|l|l|c|c|}
\hline \multicolumn{1}{|c|}{ Equipment } & Working Conditions & $\begin{array}{c}\text { Measured } \\
\text { acceleration } \\
\mathbf{m} / \mathbf{s}^{\mathbf{2}}\end{array}$ & $\begin{array}{c}\text { Declared } \\
\text { acceleration } \\
\mathbf{m} / \mathbf{s}^{\mathbf{2}}\end{array}$ \\
\hline $\begin{array}{l}\text { Roto-orbital } \\
\text { grinder one-hand } \\
\text { held air powered } \\
\text { (case A) }\end{array}$ & $\begin{array}{l}\text { Grindig wood preformed } \\
\text { structure }\end{array}$ & 4,35 & Less than 2,5 \\
\hline $\begin{array}{l}\text { Roto-orbital } \\
\text { grinder one-hand } \\
\text { held air powered } \\
\text { (case B) }\end{array}$ & $\begin{array}{l}\text { Grindig resins preformed } \\
\text { objects }\end{array}$ & 5,85 & Less than 2,5 \\
\hline $\begin{array}{l}\text { Electric powered } \\
\text { drill \& screwdriver }\end{array}$ & $\begin{array}{l}\text { Locking iron preformed } \\
\text { bars (screwing) }\end{array}$ & 3,40 & Not Declared $(*)$ \\
\hline
\end{tabular}

In addition, we must honestly point out that, often, field measurements of vibration accelerations are not so easily repeatable, due to technical problems mainly related to the contact between vibration source and transducers and signal 
noise produced by cables shakings (very hard to avoid in some hand-held machinery...). So, whatever evaluation method is chosen, the uncertainty range must be evaluated and taken in account, too.

Table 2: Comparison between measures of protection previewed from directive 2002/44/CE and other references currently used in Italy. Measured values usually are checked on more than one handle. (*) From [3] it reports a span of values; it is suggested to use the maximum values supplied to achieve a prudent evaluation. (**) From: [2] it reports average values. (***) Not found, but similar to existing data on $4 \times 4$ military vehicles.

\begin{tabular}{|l|c|c|}
\hline \multicolumn{1}{|c|}{ Equipment } & $\begin{array}{c}\text { Measured values } \\
\text { span } \\
\mathbf{m} / \mathbf{s}^{\mathbf{2}}\end{array}$ & $\begin{array}{c}\text { Data bank values } \\
\mathbf{m} / \mathbf{s}^{\mathbf{2}}\end{array}$ \\
\hline Angular grinder (working metals) & $3,45-11,80$ & $2,7-\mathbf{9 , 8}\left(^{*}\right)$ \\
\hline $\begin{array}{l}\text { Motor chain saw (sawing timbers and } \\
\text { branches) }\end{array}$ & $3,50-12,30$ & $4,0-\mathbf{1 3 , 0}\left(^{*}\right)$ \\
\hline Dumper (open pit mine) & $0,55-1,00$ & $--(* * *)$ \\
\hline Loader (tyre) open pit mine & $0,70-1,30$ & $1,0 \pm 0,5\left(^{* *}\right)$ \\
\hline $\begin{array}{l}\text { Electric driven carriage loader (on paved } \\
\text { yard) }\end{array}$ & $0,35-1,15$ & $0,9 \pm 0,7\left(^{* *}\right)$ \\
\hline Two axis bus (urban track) & $0,25-0,80$ & $0,5 \pm 0,1\left(^{* *}\right)$ \\
\hline
\end{tabular}

\subsection{Modifications on existing rules}

In any case the "44" vibration EC directive will introduce important modifications to the European legislative scenario, particularly in Italy, where vibrations related risks are at present subject to quite generic dispositions. As far as Italy is concerned, we can point out two legislative actions since years 1955 and 1956, that imposed the control of "vibrations and shakings" within suitable values, in order not to cause damages to people or things, and forced medical survey for workers employing air-powered equipment or equipped with flexible axis vibrating hand-held tools. Such actions, before the European course, were mostly used by surveillance agencies as a repressive instrument to be applied after verified health damage has happened, but they were often substantially ignored by workers and managers.

The new directive guideline points out the importance of prevention and of participated approach, and is supported by specific dispositions: information and formation of workers, study of alternative or optimized working methods aimed to reduce exposure conditions, medical surveillance if requested by suspect of real risk.

The rise of the whole-body vibrations exposure levels, previously bounded among ergonomics, to real risk factor is particularly meaningful from this point of view. 


\section{Applicatory technical aspects}

\subsection{Instrumentation}

At present, we yet suffer from a generalized delay in the instrument market. First of all we feel the lack of instrumentation in full compliance with ISO or equivalent standards, suitable for an effective practical use.

Only in recent past technology has provided technically advanced PC based measurement instrumentation or multi channel analyzers with suitable features, with no need of stationary power supply, and not so delicate for daily use in potentially aggressive environments frequently met in extractive, civil, agricultural, and industrial working facilities, where they should be used for field measurement campaigns.

More handy and protected common instruments observed by the authors come from ordinary sound level meters, and lack in frequencies ranges (especially at the lower frequencies) or have a small number of effective measurement channels (normally one). This problem is sometimes solved equipping the instrumentation with a frequency scanner or, better, a multi frequency modulated signal transmission line; in this way more than one transducer at time can communicate with logical instrument in order to get all components of the acceleration vector.

Another remarkable limitation is due to relatively reduced number of weighting filters in comparison with the high number of weighting filters from ISO standards stated for the different exposure and postural conditions. Similar problems are particularly found among recording DAT equipment.
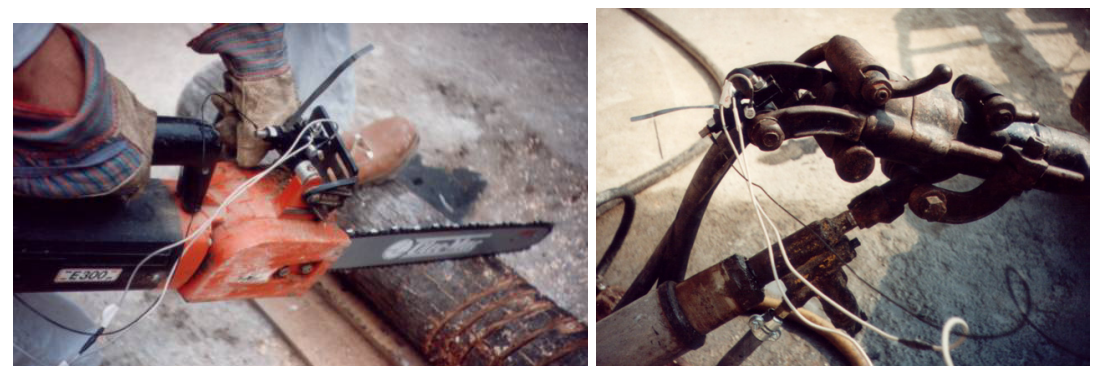

Figure 1: Field measurement conditions.

\subsection{Protection facilities}

When risk analysis is performed, a series of control measures have to be carried out and, in accordance with a consolidated logical approach, they have to start form technical control measures aimed to reduce vibration generation and propagation, up to personal protective devices or organizational and procedural measures. The basic concept is, of course, vibration damping and the solutions can be applied to structures, seats or handle through which vibrations can affect users. 
Currently it is quite difficult to find detailed data and info about protection gloves, damped seats and handle (for hand held tools) or about new methods and technologies designed to avoid vibration solicitation production. These difficulties may affect a properly selection of effective control measures or personal protective devices.

About damped seats, it is necessary to consider that usually these accessories can easily reduce vibration transmission at medium-high frequencies, but they are generally less effective in the lower frequency range (under $2-4 \mathrm{~Hz}$ ) where the solicitation may result more damaging, according with the relevant current ISO standard.

About vibration protection gloves, we can point out that effective protection can need for relevant amount of resilient material: occasionally this can be not suitable for precise handwork and for hot environments.
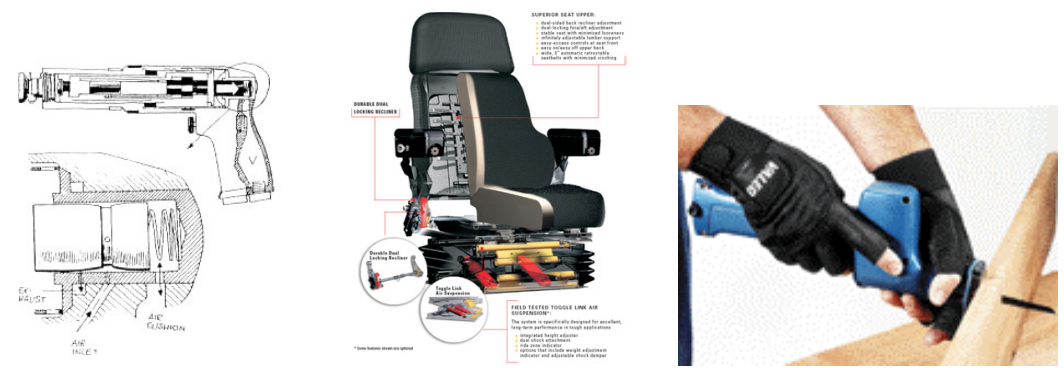

Figure 2: Possible control measures on hand held tool, seat and protective gloves (from technical documentation of manufacturer).

\subsection{Complementary factors}

As it is well known that vibration exposure effects are strictly related to other factors, as at least:

- worker's age and/or his/her experience;

- $\quad$ his/her health condition (e.g. muscoloskeletal disorders);

- micro-climates conditions (temperature and relative humidity at work);

- contemporary working conditions with possibility of cumulative trauma or overuse;

- $\quad$ working time and breaks;

- further factors influencing peripheral blood circulation (e.g. alcohol drinking, some air pollutant, and may be smoke, ...);

It is clear that a deep and complete evaluation claim for a significant wide range investigation and must be accomplished with a wide competency contribute: the technical or engineering approach should be integrated with a relevant medical evaluation of environmental factors and personal health characteristics of exposed people. 


\section{Some examples}

In the following a number of case studies is presented, in order to point out different exposure conditions, drawn form real measurement campaigns. The exposure level is given in accordance to currently available ISO standards, to be compared with EC directive requirements. Reference to manufacturer and model of machinery are voluntarily omitted.

Some picture of experimental instrumentation fitting and some result of time and frequency domain analysis are also shown (figures $3,4,5$ ).

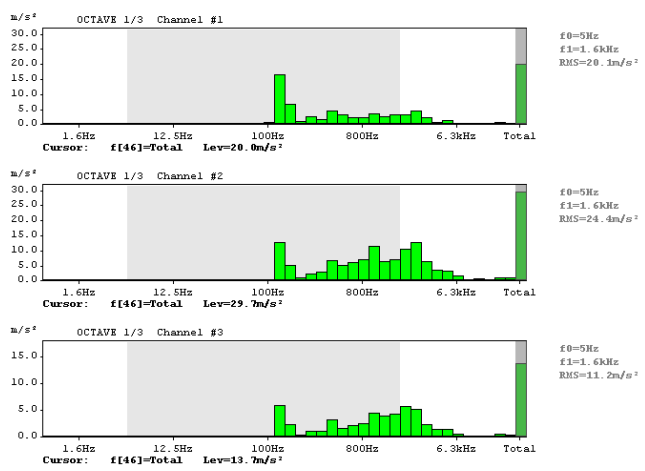

Figure 3: Back handle angular grinder: example of frequency spectra analysis in a measurement campaign.
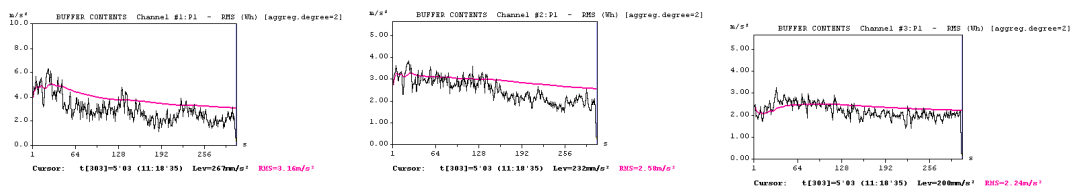

Figure 4: Back handle angular grinder: example of time history analysis in a measurement campaign.

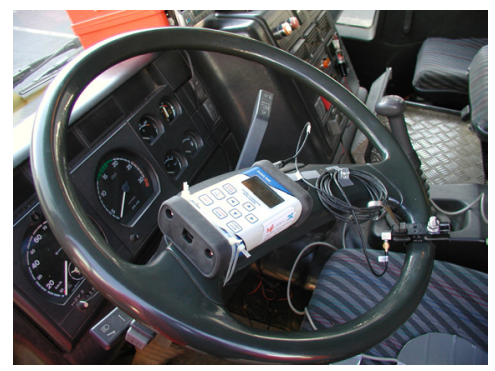

Figure 5: $\quad$ Steering wheel vibration measurement. Svantek mod. 948 analyzer with Triaxial accelerometer Dytran fitted in compliance with ISO 5349-2 requirements. 


\subsection{Case 1: Public gardens maintenance (hand-arm exposition)}

Pruning season.

Activities and equipment in a standard day.

Little chain saw (usually one hand held) time: 90 minutes $A: 3.7 \mathrm{~m} / \mathrm{s}^{2}$

Big chain saw time: $15 \quad \mathrm{~A}: 10.1 \mathrm{~m} / \mathrm{s}^{2}$

Motor hoe time: 10

A: $\quad 5.0 \mathrm{~m} / \mathrm{s}^{2}$

Branch cutting tool time: 5

A: $\quad 8.9 \mathrm{~m} / \mathrm{s}^{2}$

Remaining time: Not exposed

$$
\text { A(8) calculated (ISO 5349): } 2.7 \mathrm{~m} / \mathrm{s}^{2}
$$

\subsection{Case 2: Public bus driver (whole body exposition)}

Urban tracks, with rails crossing and partial rock slab paving roads.

Activities and equipment in a standard day.

Driving:

time: 300 minutes

A: $\quad 0.75 \mathrm{~m} / \mathrm{s}^{2}$

Remaining time: Not exposed

$$
\mathrm{A}(8) \text { calculated (ISO 2631): } 0.59 \mathrm{~m} / \mathrm{s}^{2}
$$

\subsection{Case 3: Public bus driver (hand-arm exposition)}

Sub - urban tracks. Hand arm vibration on steering wheel.

Activities and equipment in a standard day.

Driving:

time: 270 minutes

A: $\quad 3.5 \mathrm{~m} / \mathrm{s}^{2}$

Remaining time: Not exposed

$$
\text { A(8) calculated (ISO 5349): } 2.6 \mathrm{~m} / \mathrm{s}^{2}
$$

\subsection{Case 4: Truck driver (whole body exposition)}

Activities and equipment in a standard day.

Driving (urban tracks): $\quad$ time: 132 minutes

A: $\quad 0.7 \mathrm{~m} / \mathrm{s}^{2}$

Driving (trash container loading): time: 240 minutes

A: $\quad 0.32 \mathrm{~m} / \mathrm{s}^{2}$

Driving (off road tracks - dump site): time: 20 minutes

A: $\quad 0.49 \mathrm{~m} / \mathrm{s}^{2}$

Remaining time: Not exposed

$$
\mathrm{A}(8) \text { calculated (ISO } 2631 \text { ): } 0,37 \mathrm{~m} / \mathrm{s}^{2}
$$




\subsection{Case 5: Public bus driver (hand-arm exposition)}

Hand arm vibration on steering wheel

Activities and equipment in a standard day.

Driving (urban tracks): time: 132 minutes

A: $\quad 1.21 \mathrm{~m} / \mathrm{s}^{2}$

Driving (trash container loading): time: 240 minutes

A: $\quad 0.85 \mathrm{~m} / \mathrm{s}^{2}$

Driving (off road tracks - dump site): time: 20 minutes

A: $\quad 1.61 \mathrm{~m} / \mathrm{s}^{2}$

Remaining time: Not exposed

$\mathrm{A}(8)$ calculated (ISO 5349): $1,18 \mathrm{~m} / \mathrm{s}^{2}$

\section{Final remarks}

Finally, we have to point out that threshold limits proposed in the EC directive are quite easily reached in a normal working situation, at least for the lower threshold of action $\left(\mathrm{A}(8)=2,5 \mathrm{~m} / \mathrm{s}^{2}\right.$ for hand-arm exposure and $\mathrm{A}(8)=0,5 \mathrm{~m} / \mathrm{s}^{2}$ for the whole body exposure). More difficult it should be in real life trespassing the upper exposure limits.

Hope is that the evaluation of exposure condition in order to respect compulsory limits now clearly defined, together with the growing conscience of the importance -even in terms of workers health protection- of the former directive 89/392/EEC will lead to a great impulse to the introduction of equipment specially engineered to reduce the vibrations emission at the source, to a revision of work organization and procedures, and to the improvement of the currently available individual protection devices.

\section{References}

[1] ISPESL; Linee guida per la valutazione del rischio rumore negli ambienti di lavoro, updated April 2003.

http://www.ispesl.it/linee_guida/fattore_di_rischio/rumore_eng.htm

[2] ISPESL; Linee guida per la valutazione delle vibrazioni negli ambienti di lavoro, updated may 2002.

http://www.ispesl.it/linee_guida/fattore_di_rischio/vibrazioni.htm

[3] AA.VV; Linee guida in materia di rischi da vibrazioni e da movimenti e sforzi ripetuti degli arti superiori. Regione Piemonte, Ass. Sanità Torino 1997.

[4] National Institute for Working Life North, Umeå, Sweden. http://umetech.niwl.se/vibration/ 